\title{
Phylogenetic relationship among the section Stenophora in the genus Dioscorea based on the analysis of nucleotide sequence variation in the phosphoglucose isomerase (Pgi) locus
}

\author{
Akira Kawabe $^{1}$, Naohiko T. Miyashita, ${ }^{1, *}$, and Ryohei Terauchi ${ }^{2, \dagger}$ \\ ${ }^{1}$ Laboratory of Plant Genetics, Graduate School of Agriculture, Kyoto University, \\ Sakyo-ku, Kyoto 606-01, and \\ ${ }^{2}$ Laboratory of Plant Systematics, Faculty of Science, Kyoto University, \\ Sakyo-ku, Kyoto 606-01, Japan
}

(Received 20 June 1997, accepted 24 September 1997)

\begin{abstract}
To determine the phylogenetic relationship of six species (Dioscorea gracillima, $D$. nipponica, D. quinqueloba,D. septemloba,D.tenuipes, and D.tokoro) in the section of Stenophora in the genus of Dioscorea, nucleotide sequence variation in $1073 \mathrm{bp}$ of coding region of the phosphoglucose isomerase (Pgi) locus was analyzed. Estimates of nucleotide diversity ( $\pi$ ) for $D$. gracillima, D. quinqueloba, D. tenuipes, and $D$. tokoro were $0.0020,0.0005,0.0025$, and 0.0013 , respectively. Deviation from neutrality in the pattern of polymorphism in these four species was not detected by the Tajima's test. The difference in the pattern of amino acid substitutions between divergence and polymorphism was not observed by McDonald and Kreitman test. The obtained phylogenetic trees indicated that $D$. tokoro and $D$. tenuipes belonged to a monophyletic clade, while the other four species formed a separate monophyletic group. The branch lengths of phylogenetic tree varied among species. D. nipponica had a significantly faster substitution rate compared to D. gracillima, D. quinqueloba, and $D$. septemloba.
\end{abstract}

\section{INTRODUCTION}

The genus Dioscorea, which contains about 600 species (Coursey, 1967), is the largest in the family of yam, Dioscoreaceae (Burkill, 1960). Some Dioscorea species are economically important in many regions over the world, especially in southeastern Asia and Africa (Alexander and Coursey, 1969). In Japan, D. opposita (nagaimo) is cultivated widely. Phylogenetic relationship of this genus has not been well examined because of difficulty in species identification due to a high level of polymorphism with respect to morphological characters (Okagami, 1985). Some species have two different species names for male and female plants, because all species in this genus are dioecious (Okagami, 1985).

The genus Dioscorea in the Old World was classified into 23 sections (Burkill, 1960). One of the sections, Stenophora has many ancestral characters such as rhizome. Fossil record of Stenophora is the oldest in the genus Dioscorea.

\footnotetext{
* Corresponding author.

Present address: Plant Molecular Biology Group, Biocenter, University of Frankfurt, Marie Curie Str. 9/N200, D-60439, Frankfurt am Main, Germany.
}

Therefore, this section is considered as one of the oldest in the genus Dioscorea (Burkill, 1960). Eight species of the Stenophora are naturally occurring in Japan (except Ryukyu). Among the eight species, D. septemloba, D. nipponica, and D. gracillima are distributed only in northern part of Japan, and D. tokoro, D. tenuipes, and D. quinqueloba are distributed almost all over Japan. The other two species have restricted distribution area. $D$. izuensis inhabits only in the Izu peninsula, and $D$. asclepiadea inhabits only in the southern part of Kyushu island.

In this study, nucleotide sequence variation of the phosphoglucose isomerase (Pgi) locus was analyzed. PGI (EC. 5.3.1.9) catalyzes the reversible isomerization of 6phosphoglucose and 6-phosphofructose. This is an essential metabolic reaction that precedes the sucrose biosynthesis in the cytosol. Previous allozyme studies on PGI of various organisms (reviewed in Riddoch, 1993) suggested that the PGI allozyme variation could be adaptive. The allozyme variation of PGI (for example: butterfly Colias: Watt, 1977; sea anemone Metridium: Hoffmann, 1981; blue mussel Mytilus: Hall, 1985; amphipod Gammarus: Patarnello et al., 1992) showed latitudinal clines, suggesting the association between PGI allozyme and tempera- 
ture. In addition, overdominance under certain temperature conditions (butterfly: Watt, 1977; amphipod: Patarnello et al., 1992) and directional selection for high temperature (sea anemone:Hoffmann, 1981; blue mussel: Hall, 1985) were detected.

A Japanese species D. tokoro in the section Stenophora has been investigated for the Pgi locus with respect to allozyme (Terauchi, 1990) and DNA (Terauchi et al., 1997) variations. The allozyme study of $D$. tokoro (Terauchi, 1990) showed that three major alleles (a, b, and c) of PGI existed at high frequencies in natural populations in Japan. Since allele frequencies of PGI allozymes of $D$. tokoro also show latitudinal cline, a possibility of natural selection related to temperature difference was suggested (Terauchi, 1990). However, it was shown that these three alleles were related to each other with only one replacement nucleotide substitutions, that sequence variation of the Pgi region in D. tokoro was low, and that there was an excess of replacement nucleotide polymorphism (Terauchi et al., 1997). These observed patterns of DNA and allozyme variation were explained by a neutral mutation hypothesis with the assumption of small effective size of $D$. tokoro population, without invoking balancing selection (Terauchi et al., 1997).

One of the purposes of this study is to investigate phylogenetic relationship between species of the section Stenophora based on nucleotide sequence variation of the Pgi locus. For the present study, six species, D.gracillima, D. nipponica, D. quinqueloba, D. septemloba, D. tenuipes, and $D$. tokoro were investigated. Because of difficulties in sampling, D. izuensis and D. asclepiadea were not included. The second purpose is to investigate the level and pattern of nucleotide variation at the Pgi locus within and between species of the section Stenophora. As mentioned, investigated six Dioscorea species have different distribution patterns, i. e., area and locality. If the PGI polymorphism is related to the adaptation of these Dioscorea species to temperature condition, the difference in the distribution of investigated species may be reflected in the pattern of nucleotide variation at the Pgi locus.

\section{MATERIALS AND METHODS}

Plant materials. Six species (D. gracillima Miq., D. nipponica Makino, D. quinqueloba Thunb., D. septemloba Thunb., D.tenuipes Franch. et Savat., and D. tokoro Makino) were investigated in this study. To estimate the level of polymorphism, two plants each were used for three of the species (D. tenuipes, D. quinqueloba, and D. gracillima). Since each individual was heterozygous at the DNA level at the Pgi locus, the number of sequences considered was four to obtain estimate of polymorphism for these three species. One plant each was used for the other species. All the nine plants were grown in a nursery from rhizomes which were collected from the locations shown in Table 1.

\section{Reverse Transcription-PCR and direct sequencing.} In the present study, cDNA sequence was determined because the genomic Pgi gene is too long to investigate the entire region (about six kb in Clarkia). By using cDNA sequence, the expressed Pgi genes were analyzed. The procedure of cDNA synthesis followed that described for $D$. tokoro (Terauchi et al., 1997). Fresh leaves (0.5 g) were obtained from each plant, from which total RNA was extracted, using AGPC (acid guanidinium thiocyanate-phenol-chloroform) method (Chomczynski and Sacchi, 1987). cDNA was synthesized from $2 \mu \mathrm{g}$ of total RNA by oligo-dT primed reverse transcription, using Ready-To-Go T-Primed First-Strand Kit (Pharmacia). The Pgi gene was amplified from cDNA by 30 cycles of PCR, each of cycles consisting of $1 \mathrm{~min}$ at $94^{\circ} \mathrm{C}$ (denaturing), $2 \mathrm{~min}$ at $55^{\circ} \mathrm{C}$ (annealing) and $3 \mathrm{~min}$ at $72^{\circ} \mathrm{C}$ (extension). Because of nucleotide substitutions among investigated species, primers designed for the 5 ' and 3 ' ends of $D$. tokoro cDNA sequence failed the PCR amplification of the entire Pgi of these species. Instead, we used two primers, 95.1 and 93.12 (Fig. 1) to amplify a part of the Pgi for these species. These primers were originally designed for $D$. tokoro Pgi cDNA sequence at nucleotide position 199-217 and 1326-1307, respectively (Terauchi et al., 1997). The length of the PCR product obtained from this set of primers was expected to be 1073

Table 1. List of plant materials used for this study

\begin{tabular}{llll}
\hline \hline \multirow{2}{*}{ Species } & \multirow{2}{*}{$\begin{array}{l}\text { Accession } \\
\text { number }\end{array}$} & \multicolumn{2}{c}{ Geographic origin } \\
\cline { 3 - 4 } & & Place & Prefecture \\
\hline D. tokoro & DT37 & unknown & Wakayama \\
D. tenuipes & DTE1 & Takinohai & Wakayama \\
& DTE2 & Nishino & Shiga \\
D. septemloba & DSE1 & Mt. Ooe & Kyoto \\
D. nipponica & DN1 & Iide & Niigata \\
D. quinqueloba & DQ1 & Chikatsuyu & Wakayama \\
& DQ2 & Amagase, Uji & Kyoto \\
D. gracillima & DGR1 & Koyaoka, Ayabe & Kyoto \\
& DGR2 & Shuzan, Keihoku & Kyoto \\
\hline
\end{tabular}




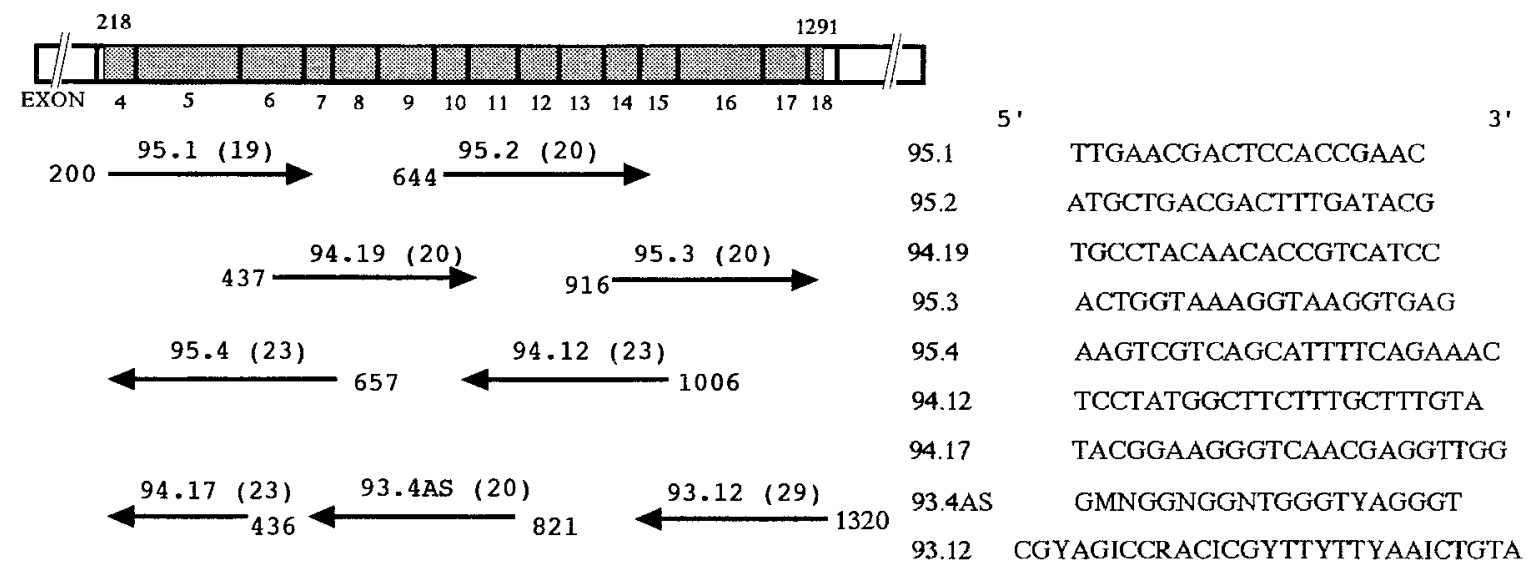

Fig. 1. Positions and nucleotide sequences of primers used for the Pgi region in this study. An arrow corresponds to the DNA region sequenced by a primer. Nucleotide position of the 5 ' end of primer is shown beside each arrow. Coordinates of the Pgi coding sequence follows Terauchi et al. (1997). Length of each primer is shown in parenthesis. Sequenced region is shown as hatched box. The exon structure is indicated.

bp long excluding the primer length. First, PCR amplification was performed in a $50 \mu \mathrm{l}$ reaction, containing total cDNA as template, $0.1 \mathrm{mM}$ each of dNTPs, 1 unit of Taq DNA polymerase (Sawady), and $50 \mathrm{pM}$ of each primer. Using $2 \mu \mathrm{l}$ of the first PCR product as template, PCR was repeated in a $100 \mu \mathrm{l}$ reaction volume containing a double amount of reagents. The second PCR product was purified by glass powder using the Geneclean II Kit (Bio101 Inc.). Purified DNAs were directly sequenced by the dideoxy chain termination method (Sanger et al., 1977) using PRISM: Dye Terminator Cycle Sequencing KIT (ABI). To sequence both strands of the 1073-bp region, nine primers (Fig. 1) were used. Some nucleotide positions were represented by two nucleotide signals, which may be heterozygous nucleotide sites, because all the species in the genus Dioscorea are outcrossing. Sites were assumed as heterozygous only when two nucleotide signals were observed in both reverse and forward sequencing reactions. The Pgi sequences of D. tokoro (DT37), D. tenuipes (DTE1), and D. quinqueloba (DQ1) were obtained from Terauchi et al. (1997). Newly obtained Pgi sequences were deposited in DDBJ data base under the accession number AB006615AB006620.

Sequence analysis. To quantify the level of nucleotide polymorphism, nucleotide diversity $(\pi$ : Nei and Li, 1979; Tajima and Nei, 1984) of D. gracillima, D. septemloba, and D. tenuipes was estimated. Tajima's test (1989) were conducted to examine the neutrality of DNA polymorphism. To conduct the intra- and interspecific comparisons of amino acid substitutions, McDonald and Kreitman's test (1991) was performed. To quantify the level of divergence between species, genetic distance was calculated by Jukes and Cantor method (d: 1969) using PHYLIP ver. 3.572 (Felsenstein, 1995) and Nei and Gojobori method $\left(\mathrm{d}_{\mathrm{N}}\right.$ and $\mathrm{d}_{\mathrm{s}}:$ 1986) using ODEN (Ina, 1992). In the above sequence analysis, we assume that heterozygous sites were due to allelic variation. Among the six species investigated, $D$. tokoro is diploid, and was shown to have a single Pgi locus per genome (Terauchi et al., 1997). On the other hand, we do not have any clear information on the polyploidy and copy number of the Pgi genes for the other five species. Therefore, estimated values of polymorphism and divergence for these five species may be biased from true values, since allelic comparison may not be done in this analysis.

Phylogenetic analysis. Nucleotide and deduced amino acid sequences of nine plants were used in phylogenetic analysis. Phylogenetic trees were constructed by neighbor-joining (NJ) method (Saitou and Nei, 1987) and a parsimony method (Fitch, 1971). NJ tree was constructed by using the Neighbor program of PHYLIP ver. 3.572 (Felsenstein, 1995) based on the genetic distances (d) between species calculated by Jukes and Cantor method (1969). Parsimony tree was constructed by using the PAUP (Swofford, 1993) with heuristic search option. The bootstrap probabilities for both $\mathrm{NJ}$ and parsimony trees were estimated for each internal branch by 100 replications. By constructing a NJ tree based on amino acid sequences of the six species and rice (as an outgroup), the root was determined for trees of nucleotide sequences. The reason for using amino acid sequence data was that synonymous nucleotide substitutions seem to be saturated between Dioscorea species and rice. Genetic distances for amino acid sequences were estimated by using Dayhoff PAM matrix (Dayhoff et al., 1979) in the PROTDIST program of PHYLIP ver. 3.572 (Felsenstein, 1995). To test the constancy of molecular evolutionary rate among lineages, Tajima's relative rate test (1993) was performed. This method is based on the chi-square test by comparing the 
Table 2. Summary of variable sites in the investigated Pgi region of the section Stenophola

\begin{tabular}{|c|c|c|c|c|c|c|c|c|c|c|c|c|c|c|c|c|c|c|}
\hline Site & ลิ & ฌึ & ڤ્ల & $\stackrel{゚}{\stackrel{ }{⿰}}$ & $\stackrel{10}{\stackrel{2}{N}}$ & ஜి & $\stackrel{\infty}{\infty}$ & ๙ి & ผึ & $\begin{array}{l}\mathscr{\wp} \\
\text { ஸे }\end{array}$ & 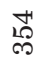 & 墭 & 10 & $\underset{\infty}{\stackrel{\infty}{\leftarrow}}$ & న్లి & 요 & $\stackrel{\infty}{\circ}$ & $\stackrel{\bullet}{\stackrel{F}{*}}$ \\
\hline Consensus & $\mathrm{A}$ & $\mathrm{C}$ & $\mathrm{G} / \mathrm{C}$ & $\mathrm{G}$ & $\mathrm{G}$ & $\mathrm{A}$ & $\mathrm{G}$ & $\mathrm{T} / \mathrm{V}$ & $\mathrm{G} / \mathrm{E}$ & $\mathrm{A}$ & $\mathrm{C}$ & $\mathrm{T}$ & $\mathrm{T} / \mathrm{V}$ & $\mathrm{C}$ & $\mathrm{G} / \mathrm{E}$ & $\mathrm{G} / \mathrm{R}$ & $\mathrm{C}$ & $\mathrm{T}$ \\
\hline DT37 & $*$ & $*$ & * & A & $*$ & * & $*$ & $\mathrm{C} / \mathrm{S}$ & $\mathrm{A} / \mathrm{K}$ & $*$ & $*$ & G & * & $*$ & $*$ & $*$ & * & $*$ \\
\hline DTE1 & $\mathrm{C}$ & $*$ & $*$ & A & $*$ & $*$ & $*$ & $*$ & $\mathrm{~A} / \mathrm{K}$ & $*$ & $\mathrm{~T}$ & G & C/A & $*$ & $*$ & $*$ & $*$ & $*$ \\
\hline DTE2 & $*$ & $*$ & $*$ & A & $*$ & $*$ & $*$ & $*$ & $\mathrm{~A} / \mathrm{K}$ & $*$ & $\mathrm{~T}$ & G & TC/A & $*$ & $*$ & $*$ & $*$ & $*$ \\
\hline DSE1 & $*$ & $*$ & $*$ & $*$ & $*$ & $\mathrm{AG}$ & $*$ & $*$ & $*$ & $*$ & $*$ & $*$ & $*$ & $*$ & * & * & $\mathrm{AC}$ & $*$ \\
\hline DN1 & $*$ & $\mathrm{~T}$ & $\mathrm{C} / \mathrm{S}$ & $*$ & $*$ & $*$ & $\mathrm{~A}$ & $*$ & $*$ & $\mathrm{G}$ & $*$ & $*$ & $*$ & $*$ & $\mathrm{~T} / \mathrm{D}$ & * & $*$ & * \\
\hline DQ1 & $*$ & $*$ & $*$ & $*$ & $*$ & $*$ & $*$ & $*$ & $*$ & $*$ & $*$ & $*$ & $*$ & $*$ & $*$ & * & $*$ & $\mathrm{C}$ \\
\hline DQ2 & $*$ & $*$ & $*$ & $*$ & $*$ & $*$ & $*$ & $*$ & $*$ & $*$ & $*$ & $*$ & $*$ & $*$ & $*$ & * & $*$ & $\mathrm{C}$ \\
\hline DGR1 & $*$ & $*$ & $*$ & $*$ & $\mathrm{~T}$ & $*$ & $*$ & $*$ & $*$ & $*$ & $*$ & $*$ & * & $*$ & $*$ & $\mathrm{~T} / \mathrm{I}$ & $*$ & $*$ \\
\hline DGR2 & $*$ & $*$ & $*$ & $*$ & $\mathrm{~T}$ & $*$ & $*$ & $*$ & $*$ & $*$ & $*$ & $*$ & $*$ & $\mathrm{~T}$ & $*$ & $\mathrm{~T} / \mathrm{I}$ & $*$ & $*$ \\
\hline
\end{tabular}

Table 2. Continued (1)

\begin{tabular}{|c|c|c|c|c|c|c|c|c|c|c|c|c|c|c|c|c|c|c|c|}
\hline พै & $\stackrel{\infty}{+}$ & 尔 & 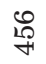 & $\begin{array}{l}\infty \\
\stackrel{1}{+} \\
\stackrel{1}{*}\end{array}$ & ֻै & $\stackrel{\infty}{\stackrel{\infty}{+}}$ & $\begin{array}{l}0 \\
1\end{array}$ & ది & 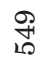 & î & హ' & ำ & §ొ & स् & $\underset{\oplus}{\infty}$ & ஜ & $\stackrel{\infty}{\mathscr{ఠ}}$ & $\stackrel{N}{O}$ & 곤 \\
\hline $\mathrm{G}$ & $\mathrm{G} / \mathrm{V}$ & A & $\mathrm{A}$ & $\mathrm{G} / \mathrm{G}$ & $\mathrm{T}$ & $\mathrm{C}$ & $\mathrm{T}$ & $\mathrm{C}$ & $\mathrm{G}$ & $\mathrm{A}$ & $\mathrm{C}$ & G/A & $\mathrm{G}$ & $\mathrm{C}$ & $\mathrm{A}$ & $\mathrm{T}$ & C/A & $\mathrm{T}$ & G/A \\
\hline$*$ & $*$ & $\mathrm{AG}$ & $*$ & $*$ & $\mathrm{C}$ & $\mathrm{T}$ & $\mathrm{A}$ & $*$ & $*$ & $*$ & $*$ & $\mathrm{~A} / \mathrm{T}$ & $*$ & $\mathrm{~T}$ & $*$ & $*$ & $*$ & $*$ & $\mathrm{~T} / \mathrm{S}$ \\
\hline$*$ & $*$ & $*$ & $*$ & $*$ & $\mathrm{C}$ & $\mathrm{T}$ & $*$ & $*$ & $*$ & $*$ & $*$ & $*$ & $*$ & $\mathrm{~T}$ & $*$ & $*$ & $*$ & $\mathrm{C}$ & $*$ \\
\hline$*$ & $*$ & $*$ & $*$ & $*$ & $\mathrm{C}$ & $\mathrm{T}$ & $*$ & $*$ & $*$ & $*$ & $*$ & $*$ & $*$ & $\mathrm{~T}$ & $*$ & $*$ & $*$ & $\mathrm{C}$ & $*$ \\
\hline$*$ & $*$ & $*$ & $*$ & $*$ & $*$ & $*$ & $*$ & $\mathrm{~T}$ & $*$ & $*$ & $*$ & $\mathrm{~A} / \mathrm{T}$ & $\mathrm{A}$ & $*$ & $*$ & $*$ & $\mathrm{G} / \mathrm{G}$ & $*$ & $*$ \\
\hline$*$ & $\mathrm{~A} / \mathrm{M}$ & * & $\mathrm{T}$ & $*$ & $*$ & $*$ & $*$ & $\mathrm{~T}$ & A & $*$ & $\mathrm{~T}$ & $*$ & $*$ & $*$ & $\mathrm{~T}$ & A & $\mathrm{G} / \mathrm{G}$ & $*$ & $*$ \\
\hline A & $*$ & $*$ & $\mathrm{G}$ & $*$ & $*$ & $*$ & $*$ & $*$ & $*$ & $\mathrm{G}$ & $*$ & $*$ & $*$ & $*$ & $*$ & $*$ & $\mathrm{G} / \mathrm{G}$ & $*$ & $*$ \\
\hline $\mathrm{A}$ & $*$ & $*$ & $\mathrm{G}$ & $\mathrm{A} / \mathrm{D}$ & * & $*$ & * & $*$ & $*$ & $\mathrm{G}$ & $*$ & $*$ & $*$ & $*$ & $*$ & $*$ & $\mathrm{G} / \mathrm{G}$ & $*$ & $*$ \\
\hline$*$ & $*$ & $*$ & $*$ & $*$ & * & $*$ & * & $*$ & $*$ & $*$ & $*$ & $*$ & $*$ & * & $*$ & $*$ & $\mathrm{G} / \mathrm{G}$ & $*$ & $*$ \\
\hline$*$ & $*$ & $*$ & $*$ & $*$ & $*$ & $*$ & $*$ & $*$ & $*$ & $*$ & $*$ & $*$ & $*$ & $*$ & $*$ & $*$ & $\mathrm{G} / \mathrm{G}$ & $*$ & $*$ \\
\hline
\end{tabular}

Table 2. Continued (2)

\begin{tabular}{|c|c|c|c|c|c|c|c|c|c|c|c|c|c|c|c|c|c|c|c|}
\hline$\underset{12}{\mathbb{2}}$ & 동 & $\underset{N}{\mathbb{N}}$ & 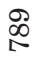 & 5 & $\underset{\infty}{\infty}$ & $\begin{array}{l}\stackrel{1}{N} \\
\infty\end{array}$ & $\underset{+\infty}{+\infty}$ & $\begin{array}{l}10 \\
10 \\
\infty\end{array}$ & $\begin{array}{l}\bullet \\
\infty \\
\infty\end{array}$ & $\begin{array}{l}-1 \\
\infty\end{array}$ & - & ஓ̊ & ஜ̊ & $\stackrel{\text { ஜூ }}{\circ}$ & ஓ & $\stackrel{ }{\sigma}$ & $\begin{array}{l}\stackrel{\leftrightarrow}{N} \\
\text { बे }\end{array}$ & సิ & ふั \\
\hline $\mathrm{T}$ & $\mathrm{C}$ & $\mathrm{T}$ & $\mathrm{T}$ & $\mathrm{C}$ & $\mathrm{C}$ & $\mathrm{T}$ & $\mathrm{A}$ & $\mathrm{T}$ & $\mathrm{T}$ & $\mathrm{T}$ & $\mathrm{A}$ & $\mathrm{T} / \mathrm{N}$ & $\mathrm{A}$ & $\mathrm{T}$ & A & $\mathrm{C}$ & $\mathrm{C} / \mathrm{T}$ & $\mathrm{T}$ & $\mathrm{T}$ \\
\hline $\mathrm{C}$ & $\mathrm{T}$ & $*$ & $*$ & $*$ & $*$ & $*$ & $*$ & $*$ & $\mathrm{C}$ & $\mathrm{G}$ & $\mathrm{G}$ & $*$ & $*$ & $*$ & $*$ & $*$ & $*$ & $*$ & $*$ \\
\hline$*$ & $\mathrm{~T}$ & A & $*$ & $*$ & $*$ & $*$ & $\mathrm{G}$ & $*$ & $*$ & $*$ & $*$ & $*$ & $\mathrm{G}$ & A & $*$ & $*$ & $*$ & $*$ & $*$ \\
\hline$*$ & $\mathrm{~T}$ & A & $*$ & $*$ & $*$ & $*$ & $\mathrm{G}$ & $*$ & $*$ & $*$ & $*$ & $*$ & $*$ & A & $*$ & $*$ & $*$ & $*$ & $*$ \\
\hline$*$ & $*$ & $*$ & $*$ & $*$ & $*$ & $*$ & $*$ & $*$ & $*$ & $*$ & $*$ & $*$ & $*$ & $*$ & $*$ & $*$ & $*$ & $*$ & $*$ \\
\hline$*$ & $*$ & $*$ & $*$ & $\mathrm{~T}$ & $\mathrm{~T}$ & $*$ & $*$ & $*$ & $*$ & $*$ & $*$ & $*$ & $*$ & $*$ & $\mathrm{~T}$ & $\mathrm{~T}$ & $\mathrm{~T} / \mathrm{I}$ & $*$ & * \\
\hline$*$ & $*$ & $*$ & $\mathrm{C}$ & $*$ & $\mathrm{~T}$ & $*$ & $*$ & $*$ & $*$ & $*$ & $*$ & $\mathrm{G} / \mathrm{K}$ & $*$ & $*$ & $*$ & $\mathrm{~T}$ & $*$ & $*$ & $*$ \\
\hline$*$ & $*$ & $*$ & $\mathrm{C}$ & $*$ & $\mathrm{~T}$ & $*$ & $*$ & $*$ & $*$ & $*$ & $*$ & $\mathrm{G} / \mathrm{K}$ & $*$ & $*$ & $*$ & $\mathrm{~T}$ & $*$ & $*$ & $*$ \\
\hline$*$ & $*$ & $*$ & $*$ & $*$ & $*$ & $\mathrm{C}$ & $*$ & $*$ & $*$ & $*$ & $*$ & $*$ & $*$ & $*$ & $*$ & $*$ & $*$ & $\mathrm{~A}$ & $\mathrm{C}$ \\
\hline$*$ & $*$ & $*$ & $*$ & $*$ & $*$ & $\mathrm{C}$ & $*$ & $\mathrm{GT}$ & $*$ & $*$ & $*$ & $*$ & $*$ & $*$ & $*$ & $*$ & $*$ & $*$ & C \\
\hline
\end{tabular}

Table 2. Continued (3)

\begin{tabular}{|c|c|c|c|c|c|c|c|c|c|c|c|c|c|c|c|c|c|c|c|}
\hline ஜ̊ & ठే & ஜ̊ & $\underset{\sim}{\stackrel{ }{ }}$ & $\begin{array}{l}\text { N } \\
\text { 응 } \\
\text { - }\end{array}$ & \begin{tabular}{l}
\multirow{1}{*}{} \\
ठै
\end{tabular} & ठే & 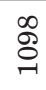 & $\underset{\overbrace{}}{\stackrel{\circ}{\circ}}$ & $\begin{array}{l}\text { न } \\
\text { ન }\end{array}$ & $\stackrel{\rho}{\stackrel{\sigma}{二}}$ & $\begin{array}{l}\text { I } \\
\text { 극 }\end{array}$ & 告 & 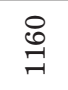 & $\begin{array}{l}10 \\
\infty \\
\end{array}$ & $\begin{array}{l}\stackrel{\infty}{N} \\
\stackrel{N}{\sim}\end{array}$ & 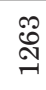 & $\begin{array}{l}\text { \&્) } \\
\text { ㄱ }\end{array}$ & $\stackrel{\stackrel{N}{N}}{\underset{\sim}{N}}$ & $\begin{array}{l}\stackrel{\sim}{\sim} \\
\stackrel{\sim}{\sim}\end{array}$ \\
\hline A & $\mathrm{T}$ & $\mathrm{C} / \mathrm{R}$ & $\mathrm{C}$ & $\mathrm{C} / \mathrm{A}$ & $\mathrm{T}$ & $\mathrm{A}$ & $\mathrm{C}$ & $\mathrm{T} / \mathrm{S}$ & $\mathrm{A} / \mathrm{I}$ & $\mathrm{T}$ & $\mathrm{A} / \mathrm{T}$ & $\mathrm{C} / \mathrm{P}$ & $\mathrm{A} / \mathrm{T}$ & A & $\mathrm{G} / \mathrm{V}$ & A & $\mathrm{G}$ & A & $\mathrm{G}$ \\
\hline$*$ & $*$ & $*$ & $*$ & $*$ & $*$ & $*$ & $*$ & $*$ & $\mathrm{G} / \mathrm{V}$ & $*$ & $*$ & $*$ & $*$ & $*$ & $*$ & $*$ & $\mathrm{~T}$ & $*$ & $*$ \\
\hline$*$ & $*$ & $*$ & $*$ & $*$ & $*$ & $*$ & $*$ & $\mathrm{~A} / \mathrm{T}$ & $\mathrm{G} / \mathrm{V}$ & $*$ & * & $\mathrm{T} / \mathrm{S}$ & $*$ & $*$ & $\mathrm{~A} / \mathrm{I}$ & $*$ & $*$ & $*$ & $*$ \\
\hline * & $*$ & $*$ & $*$ & $*$ & $*$ & $*$ & $*$ & $*$ & $\mathrm{G} / \mathrm{V}$ & $*$ & * & $*$ & $*$ & $*$ & $\mathrm{~A} / \mathrm{I}$ & $*$ & $*$ & $*$ & $*$ \\
\hline$*$ & $*$ & $\mathrm{G} / \mathrm{G}$ & $*$ & * & $*$ & $\mathrm{AC}$ & $*$ & $*$ & $\mathrm{~T} / \mathrm{F}$ & $\mathrm{G}$ & $*$ & $*$ & $*$ & $\mathrm{G}$ & $*$ & $\mathrm{G}$ & $*$ & $*$ & $*$ \\
\hline$*$ & $\mathrm{C}$ & $\mathrm{G} / \mathrm{G}$ & $*$ & $\mathrm{G} / \mathrm{G}$ & A & $*$ & $\mathrm{G}$ & $*$ & $*$ & $*$ & G/A & $*$ & $\mathrm{C} / \mathrm{P}$ & $*$ & $*$ & $*$ & $*$ & AG & $*$ \\
\hline$*$ & $*$ & $\mathrm{G} / \mathrm{G}$ & $\mathrm{T}$ & $*$ & $\mathrm{C}$ & $*$ & $*$ & $*$ & $*$ & $*$ & $*$ & $*$ & $*$ & $*$ & $*$ & * & $*$ & $*$ & * \\
\hline$*$ & $*$ & $\mathrm{G} / \mathrm{G}$ & $\mathrm{T}$ & $*$ & $\mathrm{C}$ & $*$ & $*$ & $*$ & $*$ & $*$ & $*$ & $*$ & $*$ & $*$ & $*$ & $*$ & $*$ & $*$ & * \\
\hline $\mathrm{AG}$ & $*$ & $*$ & $*$ & $*$ & $*$ & $*$ & $*$ & $*$ & $*$ & $*$ & $*$ & $*$ & $*$ & $*$ & $*$ & $*$ & $*$ & $*$ & A \\
\hline $\mathrm{G}$ & $*$ & $*$ & $*$ & $*$ & $*$ & $*$ & $*$ & $*$ & * & $*$ & * & $*$ & $*$ & $*$ & $*$ & $*$ & $*$ & $*$ & $\mathrm{~A}$ \\
\hline
\end{tabular}

Asterisk means the same nucleotide as the consensus. Two letters are used in the site that is heterozygous. In the case of replacement substitutions, one letter code of amino acid is shown after the slash. 
total number of different sites in aligned three sequences. In this test, there are two different methods, $1 \mathrm{D}$ and $2 \mathrm{D}$ methods. The 1D method was to compare the number of different sites among compared two species, while the $2 \mathrm{D}$ method was to compare the number of different sites by separating transitions and transversions among compared two species. The $2 \mathrm{D}$ method provides a more reliable test result to detect the difference in evolutionary rate if rates of transition and transversion are different (Tajima, 1993).

\section{RESULTS}

Sequence variation in the Pgi locus among species in the section Stenophora. The summary of variable sites is shown in Table 2 . There are 78 variable sites in the sample of nine individuals of six species (nine sequences). All these differences were caused by nucleotide substitutions. No length variations and frame shifts were detected. Of these sites, 15 sites were detected within species (eleven are synonymous and four are replacement substitutions) and 63 sites were found between species (46 are synonymous and 17 are replacement substitutions). The Pgi sequences of rice (Nozue et al., 1996), Arabidopsis thaliana (Thomas et al., 1993), and Clarkia lewisii (Thomas et al., 1992) can be aligned with the Dioscorea sequences. There is no change in the size of the reading frame in the investigated region among these distant species.

The levels of polymorphism within species and divergence between species are summarized in Tables 3 and 4 . Although $D$. quinqueloba has a relatively low nucleotide diversity, estimates of the other three species are similar to each other. But these estimates are lower than those of the coding regions in nuclear genes in other plant species (C. lewisii (Pgi), 0.0053:Thomas et al., 1993; Arabis gemmifera (Adh), 0.0055: Miyashita et al., 1996; A. thaliana (Adh),

Table 3. Summary of polymorphism in the Pgi locus of Dioscorea species

\begin{tabular}{llcccc}
\hline \hline \multicolumn{1}{c}{ Species } & & \multicolumn{3}{c}{ The number of polymorphic sites } \\
\hline D. tokoro* & & $\pi$ & Tajima's D & syn & rep \\
D. tenuipes & $(\mathrm{n}=20)$ & 0.0015 & 0.3225 & 2 & 4 \\
D. quinqueloba & $(\mathrm{n}=4)$ & 0.0030 & 1.5406 & 2 & 3 \\
D. gracillima & $(\mathrm{n}=4)$ & 0.0006 & 1.6330 & 0 & 1 \\
D. septemloba & & $(0.0022$ & 0.6501 & 4 & 0 \\
D. nipponica & & $(0.0009)^{\dagger}$ & & 3 & 0 \\
\hline
\end{tabular}

$\pi$ is the nucleotide diversity (Nei and Li, 1979; Tajima and Nei, 1984), Tajima's D is the statistics of Tajima's test (1989), and $\mathrm{n}$ is the number of alleles compared.

* Recalculated from Terauchi et al. (1997), ${ }^{\dagger}$ The proportion of heterozygous sites.

Table 4. Summary of divergence in the Pgi locus between species

\begin{tabular}{|c|c|c|c|c|c|c|c|}
\hline & & \multicolumn{3}{|c|}{ Genetic distances* } & \multirow[b]{2}{*}{$\mathrm{d}_{\mathrm{N}} / \mathrm{d}_{\mathrm{S}}$} & \multicolumn{2}{|c|}{$\begin{array}{c}\text { The number of fixed } \\
\text { substitutions }\end{array}$} \\
\hline \multicolumn{2}{|c|}{ Comparison of species } & $d$ & $\mathrm{~d}_{\mathrm{N}}$ & $\mathrm{d}_{\mathrm{S}}$ & & syn & rep \\
\hline D. tokoro & vs D.tenuiptes & 0.0184 & 0.0073 & 0.0575 & 0.127 & 11 & 4 \\
\hline D. tokoro & vs D. septemloba & 0.0218 & 0.0073 & 0.0704 & 0.104 & 16 & 6 \\
\hline D. tokoro & vs $D$. nipponica & 0.0402 & 0.0174 & 0.1198 & 0.145 & 26 & 14 \\
\hline D. tokoro & vs $D$.quinqueloba & 0.0258 & 0.0104 & 0.0881 & 0.118 & 21 & 8 \\
\hline D. tokoro & vs $D$. gracillima & 0.0252 & 0.0086 & 0.0835 & 0.103 & 16 & 7 \\
\hline D. tenuipes & vs D. septemloba & 0.0232 & 0.0098 & 0.0706 & 0.139 & 16 & 6 \\
\hline D.tenuipes & vs $D$. nipponica & 0.0398 & 0.0172 & 0.1201 & 0.143 & 27 & 12 \\
\hline D.tenuipes & vs $D$.quinqueloba & 0.0280 & 0.0104 & 0.0883 & 0.118 & 20 & 6 \\
\hline D.tenuipes & vs $D \cdot$ gracillima & 0.0227 & 0.0089 & 0.0738 & 0.121 & 15 & 5 \\
\hline D. septemloba & vs $D$. nipponica & 0.0266 & 0.0110 & 0.0794 & 0.139 & 19 & 9 \\
\hline D. septemloba & vs $D$.quinqueloba & 0.0170 & 0.0043 & 0.0577 & 0.075 & 14 & 3 \\
\hline D. septemloba & vs $D$.gracillima & 0.0137 & 0.0049 & 0.0449 & 0.109 & 9 & 4 \\
\hline D. nipponica & vs $D$.quinqueloba & 0.0266 & 0.0104 & 0.0795 & 0.131 & 19 & 8 \\
\hline D. nipponica & vs $D$. gracillima & 0.0290 & 0.0110 & 0.0927 & 0.119 & 19 & 9 \\
\hline D. quinqueloba & vs $D$. gracillima & 0.0175 & 0.0043 & 0.0620 & 0.069 & 12 & 4 \\
\hline
\end{tabular}

* $d$, the average number of substitutions per site, by Jukes and Cantor method (1969); $d_{N}$, the number of nonsynonymous substitutions per site; and $d_{S}$, the number of synonymous substitutions per sites. $d_{N}$ and $d_{S}$ were calculated by the method of Nei and Gojobori (1986). 
(A)

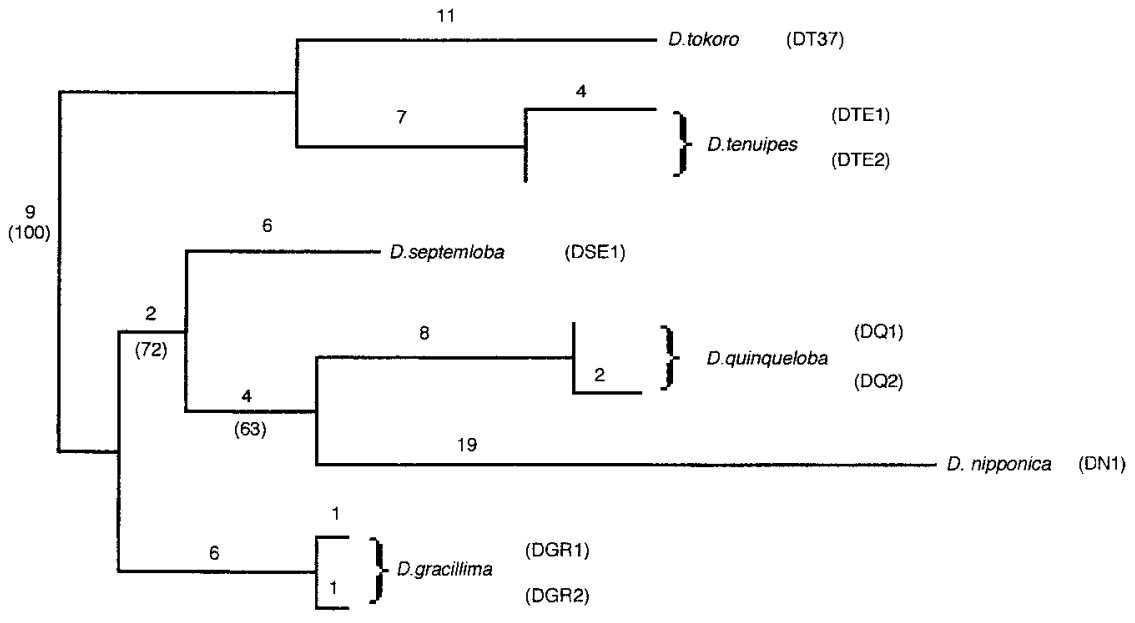

(B)
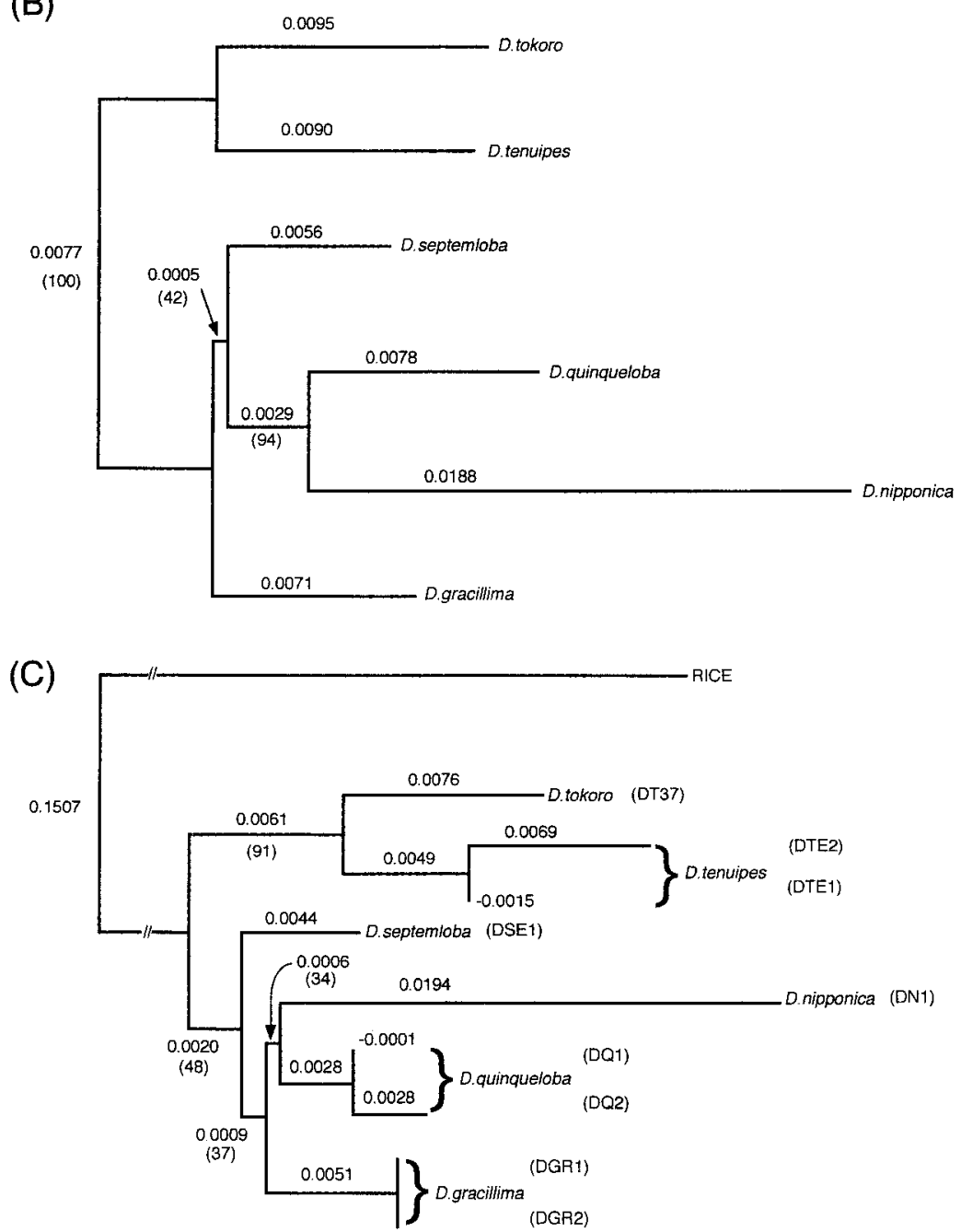

Fig. 2. Phylogenetic trees based on the nucleotide and amino acid sequence data of the Pgi region. The bootstrap probability for internal branch is shown in parenthesis. Accession number is shown in parenthesis after species name. (A) The most parsimonious tree. The number of changes is shown on branch. Consistency index and retention index are 0.950, and 0.917, respectively. (B) NJ tree based on nucleotide sequences of the Pgi. Branch length is shown above branch. (C) NJ tree based on deduced amino acid sequence data. Branch length is shown above branch. 
0.0056: Innan et al., 1996). Tajima's D value for D. tokoro, D. tenuipes, D. quinqueloba and D. gracillima in 1073-bp region were $0.3225,1.5406,1.6330$, and 0.6501 , respectively. None of the tests were signifi-cant. This result indicates that the pattern of nucleotide polymorphism does not deviate from the test assumptions, namely neutrality and population equilibrium, in any of these species. It should be mentioned, however, that these tests may not have enough power to detect the deviation from the test assumptions, because of small sample size.

$D$. gracillima, D. septemloba, and D. nipponica have only synonymous polymorphic sites, while $D$. tokoro, $D$. tenuipes, and $D$. quinqueloba have more replacement polymorphic sites than synonymous polymorphic sites. All the interspecific comparisons have two to five folds larger synonymous substitutions than replacement substitutions. To examine differences in the pattern of amino acid substitutions within and between species, MK test (McDonald and Kreitman, 1991) was performed. As for the divergence, interspecific comparison was done between Dioscorea species, and polymorphism data were obtained for the four Dioscorea species. All possible combinations of between and within species comparisons were examined by MK test, but none of comparisons were significant. The results indicated no significant difference in the pattern of amino acid substitutions in the Pgi coding region within and between Dioscorea species.

All the $d_{N} / d_{S}$ ratios are much smaller than one (Table 4). There is no indication of adaptive evolution at the Pgi locus of Stenophora species investigated. It is noted that genetic distances between $D$. nipponica and any other Dioscorea species are relatively larger than the other (Table 4). However, the $d_{N} / d_{S}$ ratios for comparison involving with
D. nipponica do not seem to be markedly larger than others, because both $\mathrm{d}_{\mathrm{N}}$ and $\mathrm{d}_{\mathrm{S}}$ for $D$. nipponica are large.

Phylogenetic analysis. Figure 2 shows the phylogenetic trees of the investigated Dioscorea species based on the Pgi sequence variations. Figure $2 \mathrm{~A}$ is the tree obtained by a parsimony analysis by using PAUP. The parsimony analysis of nucleotide sequences of the 1073-bp Pgi region in Dioscorea yielded only one most parsimonious tree with 80 steps. Figure 2B is the tree obtained by NJ method. These two trees obtained by using two different methods resulted in identical topology with two clades. One clade contains D. tokoro and D. tenuipes (clade I), and the other clade contains the other four species (clade II). Since this clustering was supported by $100 \%$ bootstrap probability for both trees, this topology could be reliable.

The NJ tree of amino acid sequence data (Fig. 2C) indicated that the root of the Stenophora species was located at the branch between the two clades. Of these two clades, one clade which consists of $D$. tokoro and $D$. tenuipes (clade I) was supported by a high bootstrap probability (91\%), but the other clade consisting of the other four species was not well supported ( $48 \%$ bootstrap probability). This result indicated that $D$. tokoro and D. tenuipes are monophyletic.

Test of constancy of evolutionary rate in the Pgi of Dioscorea. The phylogenetic trees (Fig. 2) show that the branch leading to $D$. nipponica is larger than the other branches. To test difference in evolutionary rate among species especially for $D$. nipponica, Tajima's relative rate test (Tajima, 1993) was conducted (Table 5). The outgroup species which are necessary for this test were determined from the topology of the $\mathrm{NJ}$ tree of amino acid sequences

Table 5. Results of relative rate test for the Pgi locus in Dioscorea species investigated in this study

\begin{tabular}{|c|c|c|c|c|c|c|c|c|c|c|c|c|c|}
\hline \multicolumn{2}{|c|}{ Species compared } & \multirow{2}{*}{$\begin{array}{c}\text { Outgroup } \\
3\end{array}$} & \multicolumn{9}{|c|}{ No. of different sites ${ }^{a}$} & \multicolumn{2}{|c|}{ Chi-square } \\
\hline 1 & 2 & & $\mathrm{~m} 1$ & (s1 & , v1) & $\mathrm{m} 2$ & $(\mathrm{~s} 2$ & , v2) & $\mathrm{m} 3$ & (s3 & , v3) & $1 \mathrm{D}$ & $2 \mathrm{D}$ \\
\hline D. tokoro & D.tenuipes & D. septemloba & 8.5 & 4.5 & 4 & 9.8 & 6.8 & 3 & 16.5 & 10.5 & 6 & 0.09 & 0.59 \\
\hline D. tokoro & D.tenuipes & D. nippopnica & 9.5 & 5.5 & 4 & 8.8 & 5.8 & 3 & 33.5 & 20.5 & 13 & 0.03 & 0.15 \\
\hline D. tokoro & D.tenuipes & D. quinqueloba & 9.5 & 5.5 & 4 & 8.8 & 5.8 & 3 & 20.5 & 16.5 & 4 & 0.03 & 0.15 \\
\hline D. tokoro & D.tenuipes & D. gracillima & 9.5 & 5.5 & 4 & 8.8 & 5.8 & 3 & 16.0 & 11.2 & 4.8 & 0.03 & 0.15 \\
\hline D. septemloba & D. nipponica & D. tokoro & 8.5 & 5.5 & 3 & 22.5 & 12.5 & 10 & 18.5 & 11.5 & 7 & $6.32^{\mathrm{b}}$ & $6.49^{l}$ \\
\hline D. septemloba & D. quinquieloba & D. tokoro & 8.5 & 5.5 & 3 & 10.5 & 9.5 & 1 & 18.5 & 11.5 & 7 & 0.21 & 2.07 \\
\hline D. septemloba & D. gracillima & D. tokoro & 7.5 & 3.5 & 4 & 9 & 6.2 & 2.8 & 17.5 & 11.5 & 6 & 0.14 & 1.01 \\
\hline D. nipponica & D. quinqueloba & D. tokoro & 21.5 & 11.5 & 10 & 8.5 & 7.5 & 1 & 21.5 & 14.5 & 7 & $5.63^{\mathrm{b}}$ & $8.21^{\prime}$ \\
\hline D. nipponica & D. gracillima & D. tokoro & 24.5 & 13.5 & 11 & 7 & 4.2 & 2.8 & 18.5 & 12.5 & 6 & $9.72^{\mathrm{c}}$ & 9.77 \\
\hline D. quinqueloba & D. gracillima & D. tokoro & 11.5 & 9.5 & 2 & 7 & 4.2 & 2.8 & 18.5 & 12.5 & 6 & 1.09 & 2.12 \\
\hline D. septemloba & D. nipponica & D. tenuipes & 7.5 & 4.5 & 3 & 22.5 & 12.5 & 10 & 18.8 & 12.8 & 6 & $7.50^{\mathrm{c}}$ & $7.53^{\prime}$ \\
\hline D. septemloba & D. quinqueloba & D.tenuipes & 8.5 & 5.5 & 3 & 10.5 & 9.5 & 1 & 17.8 & 11.8 & 6 & 0.21 & 2.07 \\
\hline D. septemloba & D. gracillima & D.tenupies & 9.5 & 5.5 & 4 & 7 & 4.2 & 2.8 & 16.8 & 11.8 & 5 & 0.38 & 0.39 \\
\hline D. nipponica & D. quinqueloba & D. tenuipes & 21.5 & 11.5 & 10 & 8.5 & 7.5 & 1 & 20.8 & 14.8 & 6 & $5.63^{\mathrm{b}}$ & $8.21^{\prime}$ \\
\hline D. nipponica & D. gracillima & D. tenupies & 24.5 & 13.5 & 11 & 7 & 4.2 & 2.8 & 17.8 & 12.8 & 5 & $9.72^{\mathrm{c}}$ & $9.77^{\circ}$ \\
\hline D. quinqueloba & D. gracillima & D.tenupies & 11.5 & 9.5 & 2 & 7 & 4.2 & 2.8 & 17.8 & 12.8 & 5 & 1.09 & 2.12 \\
\hline
\end{tabular}

a mi, si, and vi indicate the number of total different sites, different transition sites, and different transversion sites from other two species in species $i$, respectively ( $i=1,2$, and 3$).{ }^{\mathrm{b}}$ significant at $5 \%$ level; ${ }^{\mathrm{c}}$ significant at $1 \%$ level. 
because the root was determined (Fig. 2C). When $D$. gracillima, D. nipponica, D. quinqueloba, and D. septemloba in the clade II were compared with each other, D. tokoro or $D$. tenuipes in the clade I was used as an outgroup species. When $D$. tokoro and $D$. tenuipes in the clade I were compared, D. gracillima, D. nipponica, D. quinqueloba, or $D$. septemloba in the clade II was used as an outgroup species. In these tests, each of heterozygous nucleotide was counted as a half substitution, and average number of differences between species were used for analysis. By both 1D and 2D methods, when $D$. nipponica was compared to $D$. gracillima, D. quinqueloba or D. septemloba, significant difference was detected at the $5 \%$ level. This result indicated that $D$. nipponica had a significantly faster substitution rate than the other three species in the clade II.

\section{DISCUSSION}

DNA polymorphism at the Pgi locus in Dioscorea species. Although Dioscorea species are all dioecious (completely outcrossing), the levels of polymorphism in the $P g i$ locus region of studied species were lower than other nuclear genes in other plants. It has been shown that outcrossing plant species generally have a larger amount of polymorphism than selfing species (Hamrick et al., 1979). The present result suggest that breeding system can not be the sole reason to determine the intraspecific variation in the Dioscorea species.

As reported for the entire coding region of the Pgi in $D$. tokoro by Terauchi et al. (1997), none of Tajima's test was significant for D. tokoro, D. tenuipes, D. quinqueloba, and $D$. gracillima for the investigated 1073-bp region. This result suggests that the pattern of nucleotide variation in the $P g i$ coding region of $D$. tokoro, $D$. tenuipes, $D$. quinqueloba, and D. gracillima does not deviate from neutrality. However, in this study, the sample size is the minimum for Tajima's test, and there is uncertainly of allelism in the comparison between Pgi sequences. In future, we may need to increase the number of sequences, and to clarify the ploidy and the number of the Pgi genes per the genome of the Dioscorea species.

Divergence at the Pgi between Stenophora species. The nucleotide substitutions per site in $1073 \mathrm{bp}$ of the Pgi coding region between Dioscorea species investigated ranged from $1.4 \%$ to $4.0 \%$ (Table 4 ). These values are almost the same as those between sections of genus Clarkia (average difference $=3 \%$ : Gottlieb and Ford, 1996). In other words, nucleotide variation between Dioscorea species is as large as those between sections of other species. This result may suggest that morphological changes on which the classification of these Dioscorea species were based are slower than changes at the DNA level.

McDonald and Kreitman test (1991) conducted by Terauchi et al. (1997) showed that $D$. tokoro has an excess of polymorphic replacement sites at the Pgi locus compared to fixed replacement sites. Contrary to the result of Terauchi et al. (1997), MK test in this study was not significant for any combinations of within and between species comparisons. This result suggests that the patterns of nucleotide substitution between polymorphism and divergence are similar with respect to amino acid changes in the coding region of the Pgi of investigated species. In this study, the sample size and the number of polymorphic sites are small. These may be related to the result that any of the MK tests were not significant.

The nucleotide positions of 335 (amino acid position 112) and 713 (position 238) determine three allozymes in $D$. tokoro (Terauchi et al., 1997). These two sites were G (Gly) and A (Gln) in all the studied species, including D. tokoro (DT37). This combination of $\mathrm{G}$ and $\mathrm{A}$ at these two sites corresponds to the b allozyme of PGI in D. tokoro. This result suggests that the $b$ allozyme is the ancient form of the PGI in the Dioscorea, and that the other two a and c alleles were derived from b allele in $D$. tokoro as discussed in Terauchi et al. (1997).

Phylogenetic relationship between species in the section Stenophora. The phylogenetic trees (Fig. 2A and B) showed that investigated six species could be divided into two clades (I and II), supported by $100 \%$ of bootstrap probability. Of these two clades, the clade I consists of $D$. tokoro and $D$. tenuipes, and the clade II consists of $D$. gracillima, D. nipponica, D. quinqueloba, and D. septemloba. The clade I was also supported in the phylogenetic tree of amino acid sequence data (Fig. 2C) by a high bootstrap probability $(91 \%)$. These results indicate that D. tokoro and D. tenuipes are monophyletic.

There seems to be some, but not clear, association between the clustering pattern in the phylogenetic tree and morphology and distribution of investigated species. $D$. tokoro and $D$. tenuipes in the clade I are morphologically similar to each other. Main differences in morphology between the two species are seed and stippule shapes. This morphological similarity may be related in the clustering of these two species. Of the four species in the clade $\Pi, D$. septemloba, D. quinqueloba, and D. nipponica have lobed leaves. Although the clustering of these three species is not strong, this result suggests that species with lobed leaves may have been derived from the common ancestor with lobed leaves. Northern species (D. gracillima, D. septemloba, and D. nipponica) were included in the clade II. In addition, $D$. quinqueloba which distributes all over Japan is also included in this clade $I$. Therefore, this result suggests that nucleotide variation of the Pgi coding region does not reflect the difference in distribution pattern of species. The two species in the clade I are also distributed all over Japan. It is difficult to obtain a clear conclusion on the relationship between Pgi variation and geographic distribution from these results. 
The faster evolutionary rate of the Pgi in $D$. nipponica. The results of the relative rate test (Table 5) indicated that substitution rate was significantly faster in $D$. nipponica lineage than the other three species in the clade II. The substitution rate is determined by mutation rate and fixation probability of mutations (Kimura, 1983; $\mathrm{Li}$ and Graur, 1991). If mutations are neutral, substitution rate is equal to mutation rate. Any deviation from neutrality introduces variation in the fixation probability mainly by the effect of natural selection.

A physiological study showed that $D$. nipponica was distinct in germination response at different temperatures (Okagami and Kawai, 1982; Okagami, 1986). D. nipponica maintains a high germination rate at high temperatures without dormancy break by chilling. On the other hand, the other species (D. japonica, D. quinqueloba, $D$. septemloba, D. tenuipes, and D.tokoro) have a low germination rate at high temperatures and requires chilling for dormancy break. If the PGI enzyme is related to adaptation at different temperatures (Riddoch, 1993), the different temperature response of $D$. nipponica may be related to the significantly faster substitution rate in the Pgi locus of this species. At this moment, we do not have any clear explanation for the significantly faster evolutionary rate in the lineage of $D$. nipponica.

Authors express their thanks to T. Endo, S. Nasuda, and Y. Yasui for their comment and help. Contribution no. 547 from the Laboratory of Plant Genetics, Graduate School of Agriculture, Kyoto University.

\section{REFERENCES}

Alexander, J., and Coursey, D. G. (1969) The origins of yam cultivations. In: The Domestication and Exploitation of Plant and Animal (eds.: P. J. Ucko, and G. W. Dimbleby), pp. 405-425. Aldine Publ. Co., Chicago.

Burkill, I. H. (1960) The organography and the evolution of Dioscoreaceae the family of the Yams. J. Linn. Soc. Lond. Bot. 56, 319-412.

Chomczynski, P., and Sacchi, N. (1987) Single-step method of RNA isolation by acid guanidium thiocyanate-phenol-chloroform extraction. Anal. Biochem. 162, 156-159.

Coursey, D. G. (1967) Yams. Longman, London.

Dayhoff, M. O., Schwartz, R. M., and Orcutt, B. C. (1979) A model of evolutionary change in proteins. In: Atlas of Protein Sequence and Structure. vol. 5, suppl. 3 (ed.: D. C. Dayhof), pp. 345-352. National Biomedical Research Foundation, Washington.

Felsenstein, J. (1995) PHYLIP (Phylogeny inference package), ver 3.57. Univ. Washington Press, Seatle.

Fitch, W. M. (1971) Toward defining the course of evolution: Minimum change for aspectlic tree topology. Syst. Zool. 20, 406416.

Gottlieb, L. D., and Ford, V. S. (1996) Phylogenetic relationships among the section of Clarkia (Onagraceae) inferred from the nucleotide sequence of PgiC. Syst. Bot. 21, 45-62.

Jukes, T. H., and Cantor, C. R. (1969) Evolution of protein molecules. In: Mammalian Protein Metabolism (ed.: H. Munro) pp. 21-132. Academic Press, New York.
Hall, J. G. (1985) Temperature-related kinetic differentiation of glucose phosphate isomerase alleloenzymes isolated from the blue mussel, Mytilus edulis. Biochem. Genet. 23, 705-728.

Hamrick, J. L., Linhart, Y. B., and Mitton, J. B. (1979) Relationships between life history characteristics and electrophoretically detectable genetic variation in plants. Annu. Rev. Ecol. Syst. 10, 173-200.

Hoffmann, R. J. (1981) Evolutionary genetics of Metridium senile: I. Kinetic differences in phosphoglucose isomerase allozymes. Biochem. Genet. 19, 129-144.

Ina, Y. (1992) ODEN. National Institute of Genetics, Mishima, Japan.

Innan, H., F. Tajima, Terauchi, R., and Miyashita, N. T. (1996) Intragenic recombination in the Adh locus of the wild plant Arabidopsis thaliana. Genetics 143, 1761-1770.

Kimura, M. (1983) The Neutral Theory of Molecular Evolution. Cambridge Univ. Press, Cambridge.

Kohne, D. E. (1970) Evolution of higher organism DNA. Q. Rev. Biophys. 33, 327-375.

McDonald, J. H., and Kreitman, M. (1991) Adaptive protein evolution at the Adh locus in Drosophila. Nature 351, 652-654.

Miyashita, N. T., Innan, H., and Terauchi, R. (1996) Intra- and inter specific variation in the alchol dehydrogenase locus region of wild plants Arabis gemmifera and Arabidopsis thaliana. Mol. Biol. Evol. 13, 433-436.

Nei, M., and Li, W-S. (1979) Mathematical model for studying genetic variation in terms of restriction endonuclease. Proc. Natl. Acad. Sci. USA 76, 5269-5273.

Nei, M., and Gojobori, T (1986) Simple method for estimating the numbers of synonymous nucleotide substitutions. Mol. Biol. Evol. 3, 418-426.

Nozue, F., Umeda, M., Nagamura, Y., Minobe, Y., and Uchimiya H. (1996) Characterization of cDNA encoding for phosphoglucose isomerase of rice (Oryza sativa L.). DNA Seq. 6, 127-135.

Okagami, N. (1985)Yamu rui ni tuite no ikutuka no monndai. Jpn. J. Trop. Agric. 29, 58-63. (in Japanese).

Okagami, N. (1986) Dormancy in Dioscorea: Differnt temperature adaptation of seeds, bulbils and subterranean organs in relation to north-south distribution. Bot. Mag. Tokyo 99, 15-27.

Okagami, N., and Kawai, M. (1982) Dormancy in Dioscorea: Differences of temperature responses in seed germination among six Japanese species. Bot. Mag. Tokyo 95, 155-166.

Patarnello, T., and Battaglia, B. (1992) Glucosephosphate isomerase and fitness: effect of temperature on genotype dependent mortality and enzyme activity in two species of the genus Gammarus (Crustacea: Amphipoda). Evolution 46, 15681573.

Riddoch, B. J. (1993) The adaptive significance of electrophoretic mobility in phosphoglucose isomerase (PGI). Biol. J. Linn. Soc. 50, 1-17.

Saitou, N., and Nei, M. (1987) The neighbor-joining method: a new method for reconstructing phylogenetic trees. Mol. Biol. Evol. 4, 406-425.

Sanger, F., Nicklen, S., and Coulsen, A. R. (1977) DNA sequencing with chain-terminating inhibitors. Proc. Natl. Acad. Sci. USA 74, 5463-5467.

Swofford, D. L. (1993) PAUP: phylogenetic analysis using parsimoniony, version 3. 1. 1. Illinois Natural History Survey, Champaign, IL.

Tajima, F. (1989) Statistical test for testing the neutral mutation hypothesis by DNA polymorphism. Genetics 123, 585-595.

Tajima, F. (1993) Simple method for testing the molecular evolutionary clock hypothesis. Genetics 135, 599-607.

Tajima, F., and Nei, M. (1984) Estimation of evolutionary distance between nucleotide sequences. Mol. Biol. Evol. 1, 269-285.

Terauchi, R. (1990) Genetic diversity and population structure of 
Dioscorea tokoro Makino, a diocious climber. Plant Species Biol. 5, 243-253.

Terauchi, R., Terachi, T., and Miyashita, N. T. (1997) DNA polymorphism at the Pgi locus of a wild Yam, Dioscorea tokoro. Genetics. (in press).

Thomas, B. R., landencia-Chinguanco, D., and Gottlieb, L. D. (1992) Molecular analysis of the plant gene encoding cytosolic phosphoglucose isomerase. Plant Mol. Biol. 19, 745-757.
Thomas, B. R., Ford, V. S., Pichersky, E., and Gottlieb, L. D. (1993) Molecular characterization of duplicate cytosolic phosphoglucose isomerase gene in Clarkia and comparison to the single gene in Arabidopsis. Genetics 135, 895-905.

Watt, W.B. (1977) Adaptation at specific loci. I. Natural selection on phosphoglucose isomerase of Colias butterflies: Biochemical and population aspects. Genetics 87, 177-194. 